DIBBEN C, SAEED, H STAGIAS, K et al (2008) Crisis resolution and home treatment teams for older people with mental illness. Psychiatric Bulletin, 32 $268-270$

JOHNSON, S., NOLAN, F., PILLING, S., et al (2005) Randomised controlled trial of acute mental health care by a crisis resolution team: the north Islington crisis study. BMJ, 331, 599.

JOY, C. B., ADAMS, C. E. \& RICE, K. (2006) Crisis intervention for people with severe mental illnesses. Cochrane Database of Systematic Reviews, 18 CD001087.

*Nuwan Galappathie Specialist Registrar in Forensic Psychiatry, Fromeside, Blackberry Hill, Bristol BS161ED, email: ngalappathie@doctors. org.uk, Ragini Heeramun Specialist Trainee, Fromeside

doi: 10.1192/pb.32.11.437c

\section{Pragmatic comparison of outcome measures before and after the introduction of a crisis and home treatment service for older people}

We found admission rate decreased afte introduction of the crisis resolution and home treatment team (CRHTT; Dibben et al, 2008) but believe this was not due to bed cuts. Reducing the number of beds will reduce total number of admissions but not necessarily admission rate (total number of admissions over number of crisis events). We tested (Chi-squared) differences in this proportion and not total number of admissions per se.

Beds for older people were cut from 42 to 24. We did not examine bed occupancy but during the study period no patients were admitted out of area. Even if occupancy rate remained the same after the introduction of the CRHTT, one could argue that the CRHTTs were effective because they were operating on a total reduced in-patient capacity.

Our study is one of the first in examining the impact of CRHTTs for older adults. We mentioned that our findings are consistent with results from studies of CRHTTs in working age adults, but we do not claim that the work in general adult psychiatry is generalisable to our sample.

A research question may be answered in many ways using different epidemiological designs. We are aware a double-blind randomised control trial is the gold standard for measuring effectiveness of an intervention, but we used a pragmatic design with a 6-month period before introduction of the CRHTT as control. We defined case appropriately, compared groups at baseline, examined several outcome measures and used appropriate statistical methods, which make our findings valid and reliable.

The introduction of the CRHTT for older people, it should be noted, took place in the context of a service with wellestablished community mental health teams. A recent report from another old age psychiatry service supports the encouraging conclusions of our study (Warner \& Lowery, 2008).

DIBBEN, C., SAEED, H., STAGIAS, K., et al (2008) Crisis resolution and home treatment teams for older people with mental illness. Psychiatric Bulletin, 32 $268-270$.

WARNER, J. \& LOWERY, K. (2008) A successful older adult home treatment team. Report in Old Age Psychiatrist. Newsletter of the Faculty of the Psychiatry of Old Age, Spring, 10-11

Claire Dibben Specialist Registrar, Humera Saeed Senior House Officer, Konstantinos Stagias Senior House Officer, Golam Mohammed Khandaker Senior House Officer *Judy Sasha Rubinsztein Consultant, Older Peoples Mental Health Services, Suffolk Mental Health Partnership NHS Trust, West Suffolk Hospital, Bury St Edmunds, Suffolk IP33 2QZ, email: judy. rubinsztein@smhp.nhs.uk

doi: $10.1192 / \mathrm{pb} .32 .11 .438$ 